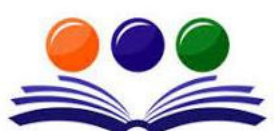

GRAND ACADEMIC PORTAL RESEARCH JOURNALS

\title{
A REVIEW ON EFFICACY OF E-LEARNING DURING PANDEMIC CRISIS
}

\author{
Heena L. Makhija \\ Ph.D. Research Scholar, \\ University School of Law, \\ Gujarat university, Ahmedabad. \\ hinamakhija25@gmail.com \\ \&
Dr. Bhavesh H. Bharad
Assistant Professor,
University School of Law,
Gujarat university, Ahmedabad. dr.bharad@gmail.com

\begin{abstract}
The severe impact of Covid-19 has shaken the world to its core. Education institution were temporarily closed in an attempt to contain the spread of covid-19 pandemic, as the consequence of which learners ranging from school going children to post graduate students were affected. Educational institution in India is currently based on traditional methods of learning that is face to face learning in classroom. Few have started moving towards the blended system of learning. This pandemic challenged the education sector and is forced to move towards the $e-$ learning. There has been a significant surge in usage of Technology such as audio, video, computer, tablets , mobile devices, blogging, webcams, whiteboards, screen casting etc in learning since Covid-19. The paper focuses on will this e-learning mean for the future, will it make part of new-normal. It studies the advantages such as cost reduction, increase convenience and flexibility, improves employee knowledge, ease of content update and disadvantages such as requirement of self-discipline and time management skills, diminished social interaction, not suitable for every topic, lack of practice based learning, reliance on technology etc of e-learning. Further it studies the challenges ranging from learner's issues, educators issue and content issues, challenges for institution to engage students and make them participate in teaching -learning process, challenges by teacher to move from offline mode to online mode, the lack of standard for quality, quality control, development of e-resource and econtent delivery ,it highlights the stipulations by government regulating e-learning, barriers in its implementation, ensuring the digital equity. Finally it ends with the conclusions and suggestions, how e-learning can be made best efficient in this time of corona era.
\end{abstract}

Keywords: Covid-19, e-learning, e-learning guidelines, Technology, India

\section{INTRODUCTION :}

COVID-19 is impacting almost every sector of the economy. Coronavirus pandemic has significantly disrupted various sectors in India including oil and gas, automobiles, aviation, agriculture, retail, etc and the education sector is no exception.According to the UNESCO Institute for Statistics, the COVID-19 pandemic has led to the closure of schools in 188 countries, affecting more than 1.5 billion students and 63 million primary and secondary teachers worldwide. The immediate solution of coronavirus is necessary or if like these days pass then closure of schools and colleges does not even have short term impact in India but can even cause farreaching economic and societal consequences. As per the assessment of the researchers, it is uncertain to get back to normal teaching anytime soon. As social distancing is preeminent at this stage, this will have negative effects on learning opportunities. Educational units are struggling to find options to deal with this challenging situation. These circumstances make us realize that scenario planning is an urgent need for academic institutions. There is an urgent need to protect and save our students, faculty, academic staff, communities, societies, and the nation as a whole. A multi-pronged strategy is necessary to manage the crisis and build a resilient Indian education system in the long term.The pandemic has transformed the centuries-old, chalk-talk teaching model to one driven by technology. This disruption in the delivery of education is pushing policymakers to figure out how to drive engagement at scale while ensuring inclusive e-learning.E-Learning can be defined as the use of computer and internet technologies to deliver a broad array of solution to enable learning and improve performance. 


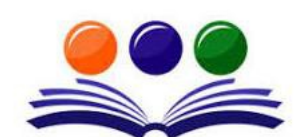

GRAND ACADEMIC PORTAL

RESEARCH JOURNALS

and formulate their own rules, based on local needs. The PRAGYATA guidelines include eight steps of digital learning that is, Plan- Review- Arrange- Guide- Yak (talk)- Assign- Track- Appreciate. These steps guide the planning and implementation of digital education step by step with examples. The Guidelines also emphasize the need to unify all efforts related to digital, online education, benefitting school going children across the country.

\section{REFERENCES:}

1. Ghirardini, B. (2011). E-learning methodologies: A guide for designing and developing e-learning courses. Food and Agriculture Organization of the United Nations.

2. https://www.jagranjosh.com/general-knowledge/impact-of-coronavirus-on-education-in-india1587642880-1.

3. https://journals.sagepub.com/doi/full/10.1177/0047239520934018.

4. http://ddnews.gov.in/national/pragyata-guidelines-digital-education-announced-hrdministry\#: :text=Union\%20Minister\%20Ramesh\%20Pokhriyal\%20Nishank,than\%2030\%20minute s\%20a\%20day

5. Rieley, J. B. (2020). Corona Virus and its impact on higher education. Research Gate.

6. Littlefield, J. (2018). The difference between synchronous and asynchronous distance learning.

7. Brianna, D., Derrian, R., Hunter, H., Kerra, B., Nancy, C. (2019). Using EdTech to enhance learning. International Journal of the Whole Child, 4(2), 57-63.

8. Barboni, L. (2019). From shifting earth to shifting paradigms: How webex helped our university overcome an earthquake. CISCO, Upshot ByInfluitive.

9. Mark, G., Semaan, B. (2008). Resilience in collaboration: Technology as a resource for new patterns of action. In Begole, B., McDonald, D. W. (Eds.), Proceedings of the 2008 ACM Conference on Computer Supported Cooperative Work (pp. 127-136). Association for Computing Machinery.

10. Mark, G., Semaan, B. (2008). Resilience in collaboration: Technology as a resource for new patterns of action. In Begole, B., McDonald, D. W. (Eds.), Proceedings of the 2008 ACM Conference on Computer Supported Cooperative Work (pp. 127-136). Association for Computing Machinery.

11. Mark, G., Semaan, B. (2008). Resilience in collaboration: Technology as a resource for new patterns of action. In Begole, B., McDonald, D. W. (Eds.), Proceedings of the 2008 ACM Conference on Computer Supported Cooperative Work (pp. 127-136). Association for Computing Machinery.

12. Affouneh, S., Salha, S., N., Khlaif, Z. (2020). Designing quality e-learning environments for emergency remote teaching in coronavirus crisis. Interdisciplinary Journal of Virtual Learning in Medical Sciences, 11(2), 1-3. 